\title{
MORE THAN WIFE ABUSE THAT HAS GONE OLD: A CONCEPTUAL MODEL FOR VIOLENCE AGAINST THE AGED IN CANADA AND THE US
}

\author{
Aysan Sev'er ${ }^{1}$ \\ Department of Sociology, University of Toronto
}

\footnotetext{
$1 \quad$ An earlier version of this paper was presented at Aging, Families \& Households in Global Perspectives Conference (May 19-23, 2008), Boston, MA. I am grateful to the Social Sciences \& Humanities Research Council of Canada (SSHRC) for generously funding my work on violence. Inquiries about the paper can be forwarded to A. Sev'er, Department of Sociology, University of Toronto, 1265 Military Trail, Scarborough, ON. Canada, M1C 1A4.
} 
On December 16, 1991, the United Nations (UN) passed resolution 46/91 to encourage the governments of the world to incorporate principals of independence, participation, care, self-fulfillment, and dignity for their aging citizens. The goal was to 'add life to the years that have been added to life' due to improved hygiene, control of infectious diseases and reduction of premature deaths (Seniors Resource, 2005). Despite the UN call for dignity for all aging populations, one of the most perplexing crimes of our time is violence against the elderly. Although people at any age and within any life cycle may be subjected to abuse, the elderly (and very young children) are exceptionally vulnerable for abuse and violence. Moreover, the nature and consequences of abuse will be different depending on the stage of life one is at, again, negatively affecting the aged (and the young) disproportionately.

\section{Types of abuse}

Violence against the aged can be divided into five types: 1. Psychological, 2. Physical, 3. Sexual, 4. Economic, and 5. Neglect. However, one should keep in mind that these clear distinctions are for analytical purposes only, since the elderly who are abused are most likely to simultaneously experience more than one kind (McDonald, Collins \& Dergal, 2006; Petterson \& Podnieks, 1995; Spencer, 1995).

Psychological abuse ${ }^{2}$ includes words, acts or gestures that demean, dehumanize, intimidate or threaten older adults (Department of Justice, 2007). Insulting the elderly, incessantly raising the issue of death with them, socially isolating them, and ordering them around and not allowing them to make decisions that they are capable of making are also part of psychological abuse. Putting down their spiritual or religious beliefs and practices, forcing the elderly to refrain from participating in the spiritual/religious ceremonies of their choice, or forcing them to participate in ceremonies they do not believe in are also considered to be abusive. In the long run, psychological abuse reduces the self-worth of the victims, and robs them of enjoyment of life and will to live (APAOnline, 2008; Canada’s Aging Population, 2002; Statistics Canada, 2005).

Physical abuse consists of intentional acts to cause pain or injury. Beating,

\footnotetext{
$2 \quad$ Some scholars include spiritual abuse under the category of psychological abuse. Others argue that
} spiritual abuse is a separate category. In this paper, spiritual abuse is seen as part of psychological abuse. 
burning or scalding, pushing, shoving, hitting and slapping are the most common forms of physical abuse (Canada's Aging Population, 2002; Department of Justice, 2007). For the elderly, tying them to heavy furniture, forcibly restraining them, locking them up or confining them to a room, forcing them to remain in beds, chairs or bathrooms are also forms of physical abuse (Department of Justice, 2007). Because of the frail condition of a large proportion of the elderly, physical abuse may take a higher toll on them, even when the used force is not extreme. For example, a strong shove may break a bone, and a broken bone in the elderly may be a cause for death. Younger people's bodies are not only more resilient against breakage, but also heal with fewer complications.

Of course, the ultimate extreme of physical abuse is lethal violence. In Canada, over one half (53\%) of homicides against older women and one quarter of those against older men are committed by their spouses or ex-spouses (Statistics Canada, 1999). Nearly half (47\%) of men who kill their wives also end up taking their own lives (Statistics Canada, 2003). Shultz (2006) and Contenta (2007) argue that murder-suicides reflect controlling and possessive attempts of the elderly (mostly husbands) over their partner's life and death, and are not acts of compassion.

Sexual abuse of elders is a type of abuse that makes the society cringe. We do not like to associate 'sexuality' with advancing ages, even when it is consensual. Moreover, we do not often believe that people who are younger and healthier would take advantage of the elderly in such perverted ways. This social discomfort with sexual abuse of the elderly often blinds us to its occurrence. In reality, elderly who are more likely to depend on care-givers (some of whom are male), who are institutionalized, who are mentally or physically unfit, or who suffer other types of violations (such as robbery, breaking \& entering) are also vulnerable to sexual transgressions. Sexual abuse may take the form of sexual assault, sexual harassment, exhibitionism or sexual exploitation (Department of Justice, 2007). A Provincial Government (Newfoundland \& Labrador) publication in Canada states that about $10 \%$ of $65+$ people with dementia are sexually abused (Violence Prevention Initiative, 2005).

Economic abuse involves financial manipulation and exploitation. It may also include theft, fraud, forgery, extortion, or charging the elderly exorbitant fees/prices for cheaper goods/services (White, 2007). The most serious form of economic abuse may 
include selling the property/homes of the elderly without their (informed) consent, stealing their pension or disability checks, and wrongfully acquiring/using their power of attorney, or forcing them to change their will (Department of Justice, 2007). Other forms of economic abuse may include forcing them to do work without pay like caring for children, or cajoling them to give money away to others. Refusing to vacate their home when asked, or residing with them without paying a fair share of the expenses are also considered as economic exploitation.

Neglect is perhaps the most common, but also the most difficult type to prove. It may be as omissions (for example, not providing care for an elder who is incapable of caring for him/herself, not providing medication that is required for chronic or acute problems) or as commissions (over medicating an elder to keep him/her docile, or putting the elder through unnecessary procedures or medical treatments). Examples of neglect include failing to provide proper nutrition or clothing, failing to attend to the hygiene of those who may be bedridden, failing to provide private bathroom arrangements, or leaving incapacitated adults unsupervised for long periods of time (Department of Justice, 2007). Neglect may also be self-inflicted (McDonald, Collins \& Dergal, 2006).

The types of abuse listed above can happen in the elders' homes or the homes of daughters/sons, where the perpetrators are intimately related to the victims (husbands, wives, adult children, grand-children, etc.), or in institutional settings (care-givers, healthcare providers, staff, etc.). In Canada, less than $7 \%$ of older people live in institutional settings (Beaulieu \& Belanger, 1995).

\section{Under-reporting}

Like child abuse and intimate partner abuse, elder abuse is also a seriously underreported crime. A large scale study conducted in the US provides insight into this matter (Administration on Aging, 1998). Of the 450,000 cases of abuse the study identified, only $16 \%$ had ever come to the attention of Adult Protection Services. Other estimates are much lower. For example Lachs and Pillemer (2004) estimate that 13/14 cases of VAA go unreported.

The reasons behind under-reporting are many. For example, the victim may be mentally or cognitively impaired, may have physical disabilities, and/or may have literacy or language problems (Canada's Aging Population, 2002). The victim may fear 
retaliation from his/her abuser, or may be totally dependent on the abuser for care. Victims may fear that others may not believe their suffering, or may fear forced institutionalization (APA-Online, 2008). There is also the shame and stigma of being a victim of abuse, especially when the abusers are intimately related to the victim (husbands, wives, adult children, grandchildren etc.). Although younger men often overreport milder forms of abuse against them and under-report their own violence against women (Dobash et al., 1995), this pattern does not necessarily hold for older men. In fact, gendered expectations may curb older men's propensity to report abuse. Men who have seen themselves (and were seen by others) as the 'dominant' partner in interpersonal relationships may find it hard to cope with their disempowerment.

Under-reporting problems are also exasperated due to strong norms about treating family life as a 'private' sphere (Croll, 2008; Eichler, 1997). Not interfering in other people's family matters is an entrenched part of the North American culture, and possible witnesses to abuse will rather stay silent than come forward on the elders' behalf. Of course, there is also the fear that they may be wrong in their suspicions/observations, and their 'altruism' may land them in an inconvenient law suit. In institutional settings, people with little training may be assigned for the care of demanding cases. Their isolated and frustrating conditions of work may reduce their sensitivity towards the people in their care (APA-Online, 2008; Department of Justice, 2007). Their own frustration may make them overly empathize with other caregivers, even when the latter cross the line.

\section{Prevalence}

Problems in reporting and the differences in definitions make elder abuse mostly a hidden crime, making the real extent of elder abuse anyone's guess. Once in a while, we get a glimpse of the problem from large, national or near national surveys that Canada or the US conducts. One such window opened to social scientific research when the Canadian Government conducted a national General Social Survey on Victimization (GSS, 1999). Of the 65+ adults who responded, 7\% reported either emotional or economic abuse by an adult child, spouse or caregiver within the last five years. Only a small percentage in this survey reported either physical or sexual abuse (1\%). However, despite its relatively low occurrence, the Uniform Crime Reports (UCR, 2000) suggest that when VAA happens, violence could be severe: For example, those who reported 
physical violence, reported being assaulted (54\%), threatened with a weapon (21\%) or assaulted with a weapon (13\%).

In the US, an early research attempt (Pillemer \& Finkelhor, 1988) found that $3.2 \%$ of a representative sample of adults had experienced some type of abuse. However, this may be the tip of an iceberg. More recently, the National Center on Elder Abuse (2005) estimated that between 1-2 million Americans who are over 65 have been injured, exploited or otherwise mistreated by someone who provides care for them. Depending on the definition (last year, last five years, or lifetime), prevalence of elder abuse ranges from $2-10 \%$ (Lachs \& Pillemer, 2004). Despite the high probability of under-reporting, in 2003, National Ombudsman Reporting System investigated almost 21,000 complaints of abuse of elderly (National Ombudsman, 2003). Moreover, probability of abuse rose with age, and the very old (85+) were much more likely to be victimized than those who were $65-85$.

\section{GENDER AND OTHER RISK FACTORS}

The risk factors for abuse can be divided into characteristics of abusers, characteristics of the victims, and circumstances. As Table I depicts, the gender variable is a risk factor for the perpetrators and victims, and may also be infused into the circumstances. Some researchers even claim that elder abuse is simply 'wife abuse' that has gone old (McDoland, Collins \& Dergal, 2006). Estimates both in Canada and the US are that $1 / 4$ to $1 / 3$ of women in relationships are victims of physical violence (Johnson, 1996; Sev'er, 2002). This ratio gets a lot higher when psychological abuse is added into the calculation. There is little reason to believe that violent men will stop their violence

just because they age. According to the Uniform Crime Reports (UCR, 2000), 71\% of the physical offences are committed by close family members, and overall, $80 \%$ of all abusers are men. However, in some cases, the opposite may also be true. That is, women who may have suffered long-term violence, may turn against their partners when they become old and frail. Either way, findings suggest that spouse abuse is much more prevalent than abuse by adult children (McDonald, 1996).

Table I about here

Thus, elder abuse is not a uniform crime, but gendered. The vast majority of perpetrators are men, and most abuse victimizes women (Lundy \& Grossman, 2004; US 
Womenshealth, ND). The reasons why gender and age combine to make older women one of the most disadvantaged groups in Canada and US are referred to as 'feminization of poverty' and include the following dimensions:

- Poverty rate for elderly women is double the rate of elderly men, and poorer people often have higher levels of dependencies, including higher health-care problems/needs (Canada's Aging Population, 2002).

- North American women live longer than men do. While most men live the last decade of their lives in the company of their female partners, most women live the last decade of their lives either alone or at the care of others. This may mean that daughters (or daughters-in-law) who may still have responsibilities for their own growing families will feel increasingly 'sandwiched' by the needs of the previous generation (Armstrong \& Armstrong, 2008; Eichler, 1997). This may also mean that women are more likely to be institutionalized, if their partners are gone, and their adult children are unable or unwilling to care for them.

A power reversal may also apply to adult children who may have been treated badly during their childhood/youth. Adult victims of childhood abuse may eventually turn their accumulated rage against aging parents. The aging process may thus evoke either an intragenerational (husband to wife/wife to husband) or an intergenerational (from children to parents) pattern of violence (Sev'er, 2002).

Until recently, $70-80 \%$ of $65+$ victims were believed to be female. More recent studies, especially for people over 80 years of age are reporting a less differentiated gender split in the incidence of violence against the aged (Canada's Aging Population, 2002). However, since women live longer than men, and since abuse increases by advancing ages, the incidence of abuse for older women will remain high (Jonson \& Akerstrom, 2004).

\section{Characteristics of abusers}

The intimate violence literature shows that intergenerational transmission of violence is a serious problem (Sev'er, 2002). Transmission does not mean that all abused children or all those who witness abuse as children will grow up to become abusers. Likewise, abusive partners (mostly men) are not likely to stop their abuse just because they or their partners have gotten old, although some do stop (Jonson \& Akerstrom, 
2004). Nevertheless, men who were abusive and controlling when they were young, will continue or escalate their abuse. Men who abuse substances like alcohol or drugs, are also likely to be abusive regardless of age. In very rare cases, abusers may suffer from mental disorders. Again, in rare cases, abusers are older women.

\section{Characteristics of victims}

As discussed earlier, gender is a risk factor. Moreover, aging people who have or who are developing physical or mental impairments are prime targets for abuse. This correlation may be due to two interrelated reasons: That the care they require may be on the increase, and the possibility they will or can report the maltreatment will be on the decline. There is also the possibility that no one will believe them, even when they do report the abuse. If they have a history of abuse (as victims or as perpetrators), the history may repeat itself, sometimes in an exacerbated form. In relatively young countries such as Canada and the US, which are racially, ethnically and linguistically heterogeneous, elders who are not proficient in the official languages of the land may also be at heightened risk (Bergin, 1995; Canada's Aging Population, 2002; Spencer, 1995). They may not be able to articulate their situation, they may not know about their rights, and/or they may not know from where to seek help.

\section{Circumstances}

A whole host of factors that are situational, social and structural could be gathered under the umbrella term of 'circumstances'. For example, isolation and lack of networks which will reduce the possibility of social comparison for victims or for their abusers are risk factors. The level of dependence on the abuser is also a risk factor, not only by raising the level of responsibility and stress, but also by reducing the ability to seek help. Karl Pillemer's (1986, also see Pillemer \& Finkelhor, 1988 and Pillemer \& Wolf, 1986) insightful work shows that the abuser's dependence on the aged is also a risk factor, where the elder will face increasing threats and demands from the younger caregiver who is economically dependent. Moreover, poverty itself is a risk factor, by increasing healthrelated problems and by reducing the likelihood of acquiring help-services or health-care. Because of continuing gender stratification, inequalities in paid and unpaid work, labour participation differences and/or segregation, aging women are also much more likely to be poor, and less prepared for the challenges that come with age (Armstrong \& 
Armstrong, 2008). The aged in the US may be more vulnerable than their Canadian counterparts since US does not provide universal health care for its citizens. In health care, Canadians, especially new immigrants to Canada are much more privileged since the state covers all necessary costs.

What is rarely discussed in the elder abuse literature is the general attitudes towards the elderly as a risk factor. In many developing societies, aging brings some accumulation of wealth. More importantly, aging brings status and respect. In the developing world, even people who may have been economically marginal throughout their lives, can gain some reverence as they age. Through accumulated knowledge and wisdom that comes with age, the scarcity of the aged due to short life expectancies, and the cultural norms that value aging as a status characteristic, the third world elderly achieve some distinction which is not available to the young.

In North America, rather than being accepted as a natural process, aging is presented as something to be avoided at all costs. Women are raised to fear the wrinkles on their faces, men learn to dread their thinning hair or enlarging guts. Multibillion dollar cosmetic industries/elective surgeries sprout to cover-up, colour, pull, nip, tuck, suck, slash, burn all signs of aging which Prosono calls the 'fascism of the skin' (Prosono, 2008; also see Wolf, 1991). Intentionally or unintentionally, governments fuel age stratification through mandatory retirement, and through the usage of terms such as 'old age' pensions/benefits, 'old age' homes and services. The advancement in information technology has also made the accumulation of knowledge aspect of the aging process almost obsolete. We live in a society where 10-year-olds have more information at their finger tips than what a 70-year-old may have accumulated in a life-time. So the culture itself marginalizes the aged.

\section{Aging in Canada \& the US}

The proportion of the aged in North America is swelling due to better health-care and increased longevity (Canada's Aging Population, 2002; Seniors Resource, 2005), and VAA is bound to become more of a social problem. In Canada, life-expectancy ${ }^{3}$ has been on the rise over the last few decades. For example, although in 1926, life-expectancy for

\footnotetext{
3 Life-expectancy is defined as the average length of time a group of individuals of the same cohort will live.
} 
men and women were 57 and 63 years respectively, in the 1950s, the corresponding numbers have reached 66 and 71 years. Currently, Canadian men and women can expect to live 77 and 84 years respectively. Corresponding US numbers are slightly lower but similar (75 versus 81 years) (Canada, 2008; CIA Facts, USA, 2008).

Apportioning of the population into young (0-14 years), middle (15-64) and older $(65+)$ age groups provides additional information. In Canada, low birth rates (1.6 per adult woman) and the rise in life-expectancy have caused a significant contraction of the $1^{\text {st }}$ (only $17 \%$ of total population) and an expansion of the $3^{\text {rd }}$ category ( $13.5 \%$ of total population). By 2030 , the $65+$ category is expected to reach over $22 \%$. US fertility rates are higher (2.1 per adult woman), thus a slightly larger proportion of the population is in the $0-14$ year group (20\%). Nevertheless, the category of $65+$ is also substantial in the US (12.5\% of total population), and is expected to rise. Table II summarizes some of these demographic facts for Canada and the US.

Table II around here

The expansion of the $65+$ group without a corresponding expansion in the middleage groups has many implications for societies within which this expansion occurs. For example, as the $65+$ group withdraws from labour force participation, it increasingly becomes the user of social safety nets and health services. Since Canada has universal healthcare coverage for all its citizens and landed immigrants, healthcare already constitutes one of its highest expenditures and the costs are on the rise. Although US has not opted for universal healthcare for its population, especially the non-affluent portion of its aged is already straining its Medicare and Medicaid systems. These patterns coupled with the moral obligation to treat the ageing populations with the dignity they deserve requires concerted efforts to address VAA.

\section{A CONCEPTUAL MODEL}

Mirroring the increased focus on aging, studies on VAA are becoming abundant, but theoretical models specific to VAA are few (see Rabiner \& O'Keeffe, 2004 as a noteworthy exception). In the literature, we often find descriptive efforts rather than predictive assertions. Some researchers borrow theories from related fields (i.e., criminology, gerontology, violence against women, child abuse), to make generalizations about VAA. For example, Situational Models—also called Stress Models — are borrowed 
from the child abuse literature, and try to explain the abuse through the stress of the caregiver (McDonald, 1996; Harbison, McKinley \& Pettipas, 2006; Pillemer \& Suitor, 1998). The difficulty is that this model ignores the structural constraints, infantilizes the victim, and places the blame on the older person as the source of stress. Others borrow concepts from the Exchange Theories to account for abuse (Glendenning, 1993; Phillips, 1986). The trouble with generalizing the exchange model to VAA is that it ignores macro-level determinants, and reduces all the aged into powerless and dependent positions. As Pillemer and colleagues (Pillemer \& Finkelhor, 1988; Pillemer \& Suitor, 1998; Pillemer \& Wolf, 1986) have shown, sometimes it is the abuser who is dependent on his/her victim, and this reversed dependency is at the root of abuse. Feminist theories claim that violence is gendered, and focus on male spouse abuse (Dobash et al., 1995; Pillemer \& Finkelhor, 1988; Podnieks, 1992). Although there is much support for feminist views, VAA has sufficient differences from violence against women, and its own social and moral importance to require its own conceptual models (Jonson \& Akerstrom, 2004).

The following model (Figure 1) is a preliminary effort towards theory development directly to address VAA. This preliminary model attempts to 1 . organize the existing knowledge, 2. explain the relationships between different levels of variables, 3 . propose directionality of cause, and 4. provide insights for how the socially problematic patterns can be broken and how positive change can occur. In addition, the model shows the complexity of the issue through combining personal, social and structural factors. In the model, personal characteristics are linked to social conditions (wide arrows from personal to social determinants), and those social conditions are likely to trigger either abusive or non abusive outcomes (wide arrows from social to abuse/no abuse outcomes). However, the model is not deterministic, since it also shows that social circumstances may also buffer (or accelerate) the likelihoods (broken lines from personal to social, and an altered link to abuse/no abuse). Likewise, structural characteristics may provide an arena where abuse is likely or unlikely to occur (wide arrows from structural to abuse/no abuse), but also may work indirectly through their impact on social factors (back arrows from structural to social, and altered links to abuse/no abuse). The positive change the model highlights can come by reducing accelerators (at all three levels) and augmenting 
the buffering factors (at all three levels).

Figure 1 around here

\section{CONCLUSIONS \& SOME SUGGESTIONS}

In affluent societies such as the US and Canada, the expansion of the aging of the population scenario discussed above focuses our attention on the following points:

- Abuse of elders, in any form, is a major social problem, and is on the rise due to changing demographics.

- VAA is a severely under-reported crime.

- VAA is gendered where the perpetrators are disproportionally men (80\%), and the victims are mostly women. Circumstances are also gendered.

- These exigencies require a new configuration of responses that prioritize the increasing needs of the aging populations. We need theoretical models such as the one proposed here, to understand the multi-layered complexity in VAA. Reaching an understanding at all three levels is necessary (personal, social and structural) to direct efforts towards prevention, and in cases where prevention fails, towards support and intervention (CPA/SCP Elder Abuse, 2008). What is important in the model is that eradication of VAA cannot be achieved through isolated efforts, or through micro level interventions.

\section{Personal \& social inhibitors and the role of awareness}

The most potent prevention tool is education and personal and public awareness about VAA (Beaulieu, 1992). At the personal level, people need to be socialized towards tolerance, respect for others and conflict resolution through non-violent means Socialization patterns, early on, must reduce the emergence of gendered inequalities. Early socialization must also instil in boys as well as girls, respect for the self and others (personal level of the model). At the social level, and through the formal educational system, importance of social networks can be highlighted (social level of the model). Pathways can be paved towards how to access social resources and how to establish social and economic efficacy. At the structural level (structural level of the model), awareness creation programs can provide much needed knowledge about community services, health-care programs, and/or knowledge about the workings of the criminal justice system (police, lawyers, judges). Thus, VAA can be taken out of being a dark 
'private' secret, and can be presented as a criminal act, and an act against human rights and social morals. Moreover, awareness programs can dismantle the artificially created public/private divides, and encourage the reporting process (the link between social and structural dimensions in the model).

\section{The responsible state and public policy}

Like all other forms of family violence (violence against children, violence against women), elder abuse is also a crime against society, rather than a 'private' family affair (Beaulieu, 1992; CPA/SCP Elder Abuse, 2008; National Centre, 2005). As the conceptual model shows, the role of a socially responsible state is paramount in the eradication of VAA. Not only should the state provide a protective environment through educational opportunities, income security, social safety networks, affordable housing etc., but also be vigilant in pursuing the criminal justice route in cases of violations. After all, personal safety and freedom from violence are irreducible human rights that are enshrined both in public mores, and in UN conventions and declarations. Signatory states to these conventions like Canada and the US, have the responsibility and obligation to proactively protect these basic rights (Lakeman, 2003).

\section{Personal, Social \& Structural Intervention}

Although the model emphasizes preventative factors, we can still generalize the tri-level approach to situations where prevention has failed. At the personal level, we need to hold individuals; at the social level, the social networks (including families); and at the structural level, the institutions responsible for reporting acts and omissions that hurt, injure, degrade or risk the safety of elders. We also need to hold the perpetrators, regardless of the relationship with their victims, accountable for their acts and omissions. At the structural level, this requires vigilance in emergency responses, police investigations, crown attorney decisions, court proceedings and, if need be, through sentencing (Lakeman, 2003). Currently, crimes against the elders remain one of the least likely reported crimes, and even when reported, form one of the least likely crimes that lead to convictions (Lakeman, 2003). A recent Canadian conviction on neglect exemplifies the role of a proactive state: The case involved a highly successful and affluent son and the neglectful death of his mother who was confined to the basement of his house. The mother was suffering from advanced stages of Alzheimer's disease, was 
severely malnourished, and had died under despicable conditions (Small, 2007). This landmark case is not about commission of a crime but recognition of omission of responsibilities as a crime.

Victims of violence, regardless of age, gender or ethnic group membership, may need individual therapy and/or group therapy support. However, the information about their rights, and know-how to access the available support systems may vary on the basis of the gender/ethnic membership or language skills. In cases where victims are too frail to fend for themselves, public NGOs or legal or para-legal groups should shoulder the responsibility to advocate for them (see Advocacy Centre, ND; Bergin, 1995). However, advocacy should not be at the expense of self efficacy of the elders, and should avoid infantilizing elders who are capable of making decisions for themselves (again, the trilevel intervention suggested by the model).

We also need to take a more reflexive position on values of the societies we have created. On the one hand, both Canada and the US take pride in presenting themselves as societies of individual rights and freedoms, their 'moral' leadership in the global community, and in being states of law and order. On the other hand, and in different degrees, they tolerate inequities, inequalities and even injustices in the areas of gender, race/ethnicity, and age. Destructive societal attitudes (isms) such as sexism, racism, ethnocentrism not only continue to exist, but also create a fertile ground for other 'isms' such as agism. In light of the demographic shifts in life expectancies, these archaic attitudes and behaviours need serious re-evaluation in the context of human rights (Eisler, 1997). Aging Americans and Canadians deserve to live their remaining lives in safety and dignity. The sad truth is that $5-10 \%$ of them are not currently able to enjoy this basic right. The conceptual model introduced in this paper invites more discussion on the multiple ways to eradicate VAA. 


\section{REFERENCES}

Administration on Aging. 1998. The National Elder Abuse Incidence Study: Final Report. Washington DC: The Administration on Aging \& National Center on Elder Abuses at the American Public Human Services Association.

Advocacy Centre for the Elderly. ND. http://www.advocacycentreelderly.org/index.htm (last visited: April, 2007)

APA Online-Elder Abuse and Neglect: In search of solutions (2008).

http://www.apa.org/pi/aging/eldabuse.html (last visited: March, 2008)

Armstrong, P. \& Armstrong, H. 2008. Bringing it Home: Women's Health Work. To appear in Women's Health \& Urban Life. VII(2), 6-15.

Beaulieu, M. 1992. Intervention for Victimized Elderly People. Quebec: Association Quebecoise.

Beaulieu, M. \& Belanger, L. 1995. Intervention in long term care institutions with respect to elder mistreatment. In M. MacLean (Ed.). Abuse and Neglect of Older Canadians (pp. 27-40). Ottawa: Thompson.

Bergin, B. 1995. Elder Abuse in Ethnocultural Communities: An Exploratory Study with Suggestions for Intervention and Prevention. Ottawa: Canadian Association of Social Workers.

Canada's Aging Population. 2002. Minister of Public Works and Government Services. [Cat. H39-608/2002E]. http://dsp.psd.communication.gc.ca/Collection/H39-6082002E.pdf (last visited: April, 2008)

CIA The World Factbook. 2008. Canada. http://www.cia.gov/library/publications/theworld-factbook/geos/ca.html (last visited: March, 2008)

CIA The World Factbook. 2008. US. http:/www.cia.gov/library/publications/the-worldfactbook/geos/us.html (last visited: March, 2008)

Contenta, S. 2007. Murder or mercy?

http://www.thestar.com/comment/columnists/article/266501 (last visited: April, 2007)

CPA/SCP Elder Abuse.

http://www.cpa.ca/public/yourhealthpsychologyworksfactsheets/elder (last visited:

March, 2008)

Croll, M.C. 2008. Following Sexual Abuse: A Social Interpretation of Identity

Re/Formation in Reflexive Therapy. Toronto: University of Toroto Press. 
Department of Justice: Abuse of older adults fact sheet (2007).

http://www.justice.gc.ca/en/ps/fm/adultsfs.html (last visited: March, 2008)

Dobash, R.P., Dobash, E.R., Cavanagh, K., \& Lewis, R. 1995. Research Evaluation Programs for Violent Men. Manchester: Violence Research Unit.

Eisler, R. 1997. Human rights and violence: Integrating the private and public spheres. In J. Turpin \& L.R. Kurtz (Ed.). The Web of Violence: From Interpersonal to Global. Urbana: U. of Illinois Press.

Eichler, M. 1997. Family Shifts. Toronto: Oxford.

Glendenning, F. 1993. What is elder abuse and neglect? In P. Decalmer \& F.

Glendenning (Eds.). The Mistreatment of Elderly People (pp. 1-34). London: Sage.

GSS (General Social Survey: A Profile of Criminal Victimization). 1999.

http://www.statcan.ca/bsolc/english/bsolc?catno=85-553-x

Harbison, J., McKinley, P. \& Pettipas, D. 2006. Older people as objects, not subjects: Theory and practice in situations of elder abuse. In R. Alaggia \& C. Vine (Eds.). Cruel but not Unusual (pp. 467-502). Waterloo, ON: Wilfrid Laurier.

Johnson, H. 1996. Dangerous Domains: Violence Against Women in Canada. Toronto: Nelson.

Jonson, H. \& Akerstrom, M. 2004. Neglect of elderly women in feminist studies of violence: A case of ageism. Journal of Elder Abuse and Neglect, 16(1), 47-64.

Kendall, D., Murray, J.L. \& Linden, R. 2004. Sociology in Our Times ( $3^{\text {rd }}$ Ed.). Toronto: Thomson.

Lachs, M.S. \& Pillemer, K.A. 2004. Elder abuse. The Lancet. 364: 1192-1263.

Lakeman, L. 2003. Canada's Promises to Keep: The Charter and Violence Against Women. Toronto: Canadian Association for Sexual Assault Centres.

Lundy, M. \& Grossman, S.F. 2004. Elder Abuses: Spouse/Intimate partner abuse and family violence among elders. Journal of Elder Abuse and Neglect, 16(1), 85-92.

McDonald, P.L. 1996. Abuse and neglect of elders. In J.E. Birren (Ed.). Encyclopedia of Gerontology: Age, Aging, and the Aged (Vol. 1). San Diego, CA: Academic Press.

McDonald, L., Collins, A. \& Dergal, J. 2006. The abuse and neglect of adults in Canada. In R. Alaggia \& C. Vine (Eds.). Cruel but not Unusual (pp. 425-466). Waterloo, ON: Wilfrid Laurier. 
National Center on Elder Abuse. 2005.

http://www.ncea.aoa.gov/ncearoot/MainSite/pdf/publication/FinalStatistics050331.pdf (last visited: March, 2008)

Patterson, C. \& Podnieks, E. 1995. A Guide to the Diagnosis and Treatment of Elder Abuses. In M. Novak (Ed.). Aging and Society: A Canadian Reader. Toronto: Nelson. National Ombudsman Reporting Syatem Data Tables. 2003. Washington, DC: US Administration on Aging.

Pillemer, K. 1986. Elder Abuses: Conflict in the Family. Auburn House Co.

Pillemer, K. \& Finkelhor, D. 1988. The prevalence of elder abuse: A random sample survey. The Gerentologist, 28: 51-57.

Pillemer, K. Suitor, J.J. 1998. Violence and violent feelings: What causes them among family caregivers? In R.K. Bergen (Ed.). Issues in Intimate Violence (pp. 255-266). Thousand Oaks, Ca.: Sage.

Pillemer, K. \& Wolf, R.S. (Eds.). 1986. Elder Abuse: Conflict in the Family. Dover, MA: Auburn House.

Phillips, L.R. 1986. Theoretical explanations of elder abuse: Competing hypotheses and unresolved issues. In K.A. Pillemer \& R.S. Wolf (Eds.). Elder Abuse: Conflict in the Family (pp. 197-217). Dover, MA: Auburn House.

Podnieks, E. 1992. National survey on abuse of the elderly in Canada. Journal of Elder Abuse \& Neglect, 4, 5-58.

Prosono, M.T. 2008. Fascism of the skin: Symptoms of alienation in the body of consumptive capitalism. Current Sociology, 56(4), 635-656.

Rabiner, D.J., O'Keeffe, J. \& Brown, D. 2004. A Conceptual Framework of financial exploitation of older persons. Journal of Elder Abuse and Neglect, 16(2), 53-74.

Seniors Resource (2005). http://www.seniorsresource.ca/docs/conference_Report.pdf (last visited, April, 2008).

Sev'er, A. 2002. Fleeing the House of Horrors: Women Who Have Left Their Abusive Partners. Toronto: University of Toronto Press.

Shultz, G. 2006. Elderly murder-suicide indicate depression, not compassion. http://www.lifesitenews.com/ldn/2006/aug/06083106.html (last visited: April, 2008)

Small, P. 2007. Landmark conviction in abused mother's death. http://www.thestar.com/News/article/179502 (last visited: April, 2008) 
Spencer, C. 1995. New directions for research on interventions with abused older adults. In M. MacLean (Ed.). Abuse and Neglect of Older Canadians: Strategies for Change (pp. 143-158). Toronto: Thompson.

Statistics Canada. 2002. Profile of the Canadian Population by Age and Sex: Canada Ages. Cat. 96 F0030XIE2001002.

http://www.12.statcan.ca/english/census01/products/analytic/companion/age/contents.cf m (last visited: April, 2005)

Statistics Canada. Family Violence in Canada: A Statistical Profile (2005). http://www. Statcan.ca/English/freepub/85-224-XIE/85-224-XIE2005000.pdf (last visited: April, 2008).

Statistics Canada. Family Violence in Canada (2003). Canadian Centre for Justice Statistics: Highlights. Cat. 85-224-XIE. Ottawa: Government of Canada.

Statistics Canada. Family Violence in Canada (1999). Canadian Centre for Justice Statistics: Highlights. Cat. 85-224-XIE. Ottawa: Government of Canada.

UCR (Uniform Crime Reports). 2000. Federal Bureau of Investigation. http://www.fbi.gov/ucr/00ius.htm (last visited: March, 2008).

US Womenshealth.gov. (ND)Violence Against Women: Elder Abuse. http://www.4women.gov/violence/groups/elder.cfm (last visited: April, 2008)

Violence Prevention Initiative. 2005. Government of Newfoundland \& Labrador. http://www. Gov.nf.ca/vpi/facts/elders.html

White, N.J. 2007. Stalking predators who prey on seniors. http://www.thestar.com/Life/Article/185591 (last visited: April, 2008)

Wolf, N. 1991. The Beauty Myth. Toronto: Vintage. 


\section{Table I. Risk Factors in Elder Abuse}

\begin{tabular}{|l|l|l|}
\hline Characteristics of Abusers & Characteristics of Victims & Circumstances \\
\hline -Gender $(80 \%$ men) & -Gender (mostly women) & -Social or geographic isolation \\
-Any adult $18+$ & $-65+$ but mostly $85+$ & -Lack of social networks \\
-Past history of abuse & -Past history of abuse & (gendered) \\
(witnessing or experiencing abuse & (witnessing or experiencing abuse & -Dependence on the abuser \\
as a victim) & as a victim) & (physical/emotional or economic, \\
-Past history of abuse( as a & -Age \& health status & -Abuser being dependent on the \\
perpetrator) & -Cognitive impairment & elder (physical/emotional or \\
-Controlling behaviour & -Physical impairment & economic) \\
-Substance dependence/abuse & -Language/communication & -Unemployment/stressful work \\
-Psychopathology (in rare cases) & difficulties & conditions of the care-giver \\
& -Powerlessness & -High stress \\
& & -Poverty (gendered) \\
& & -Institutionalization (gendered) \\
& & -Youth focused culture \\
\hline
\end{tabular}




\section{Table II. Demographic Information on Canada \& the USA}

\begin{tabular}{|l|l|l|}
\hline Variables & CANADA & USA \\
\hline Total Population & $33,390,000$ & $301,140,000$ \\
Total Fertility Rate & 1.6 & 2.1 \\
Median Life-Expectancy & 39.1 & 36.6 \\
\% of population 65+ & 13.5 & 12.5 \\
Sex Ratio at Birth & 105 males/100 females & 105 males $/ 100$ males \\
Sex Ratio in 65+ group & 75 males/100 females & 72 males $/ 100$ males \\
Overall Life Expectancy & 80.4 & 78 \\
Life Expectancy for M/W & $77(\mathrm{M})$ versus $83.9(\mathrm{~F})$ & $75(\mathrm{M})$ versus $81(\mathrm{~F})$ \\
\hline
\end{tabular}

Sources: CIA World Factbook, 2008, Canada. CIA World Factbook, 2008, US; Kendall, Murray \& Linden, 2004; Statistics Canada, 2002. 